\title{
Translational Activation
}

National Cancer Institute

\section{Source}

National Cancer Institute. Translational Activation. NCl Thesaurus. Code C29859.

Translational Activation consists of cellular and enzymatic reactions that promote the process by which polypeptides are synthesized on ribosomes from information in mRNA transcripts. 